\title{
OBTENÇÃO DO VINAGRE ORGÂNICO A PARTIR DA MALUS COMMUNIS (MAÇÃ)
}

Thainá Barbosa de Lima Cordeiro'

Raul Francisco Grasso ${ }^{2}$

Silvia Helena Kruszynski de Assis Sousa ${ }^{3}$

Resumo: - Este projeto visa o desenvolvimento e produção do vinagre, a partir da Malus communis (maçã), orgânico a através de uma reação de fermentação acética e alcoólica. O vinagre, além de estar presente no cardápio global, também é provido de benefícios medicinais, podendo ser produzido a partir da canade-açúcar, da maçã, uva, tâmaras, e dentre outras frutas e cereais. Estes procedimentos foram realizados no laboratório de Química do Colégio UNIVAP - Unidade Villa Branca. O resultado mostrou-se eficiente e acessivel, além de colaborar para sustentabilidade, auxilia na preservação da saúde do consumidor.

Palavras-chave: Vinagre; Maçã; Benefícios medicinais; Sustentabilidade.

\footnotetext{
${ }^{1}$ Técnico/Colégio Técnico UNIVAP - Villa Branca, Brasil. E-mail: thainacordeiro1@outlook.com.

2 Técnico/Colégio Técnico UNIVAP - Villa Branca, Brasil. E-mail: raulgrasso@univap.br.

3 Técnico/Colégio Técnico UNIVAP - Villa Branca, Brasil. E-mail: silviakruszynski@univap.br.
} 